\title{
A GLOBALIZAÇÃO E A PROTEÇÃO DO CONSUMIDOR COMO DIREITO FUNDAMENTAL
}

Paula Santos de Abreu

\begin{abstract}
RESUMO
O processo de tutela do consumidor desenvolveu-se paralelamente à abertura de mercados, contrapondo a idéia de que a maior proteção do consumidor equivaleria à barreira ao comércio. O estabelecimento de medidas protecionistas levou os países a produzir produtos de maior qualidade e de maior aceitação internacional, protegendo o mercado interno de produtos estrangeiros não preparados para esta competição. Em 1985, a ONU positivou o princípio da vulnerabilidade do consumidor, influenciando vários países na elaboração de suas legislações consumeristas. A preocupação com respeito aos direitos fundamentais e, conseqüentemente, com a tutela do consumidor consolida os direitos do cidadão e promove o desenvolvimento econômico e social. Por ser direito fundamental, a proteção do consumidor vincula o restante do ordenamento jurídico brasileiro. Portanto, normas que decorrerem dos acordos comerciais, que não estiverem em sintonia com nossa Constituição deverão ser desconsideradas, enquanto as que ampliarem o grau de proteção à pessoa humana têm aplicabilidade imediata, conforme a CF/ 1988. Há, ainda, longo caminho a ser percorrido em termos de harmonização ou convergência de legislações para que o consumidor esteja protegido dentro e fora dos blocos regionais. O importante é que as garantias já positivadas sejam ampliadas e não restringidas pelas novas normas internacionais.
\end{abstract}

Palavras-chaves: integração econômica, liberalização, tutela do consumidor.

\section{The globalization and the consumer protection as a fundamental right}

\begin{abstract}
The process of consumer protection has developed together with the opening of the markets, opposing to the idea that a major protection of the consumer would become a barrier to trade. In fact, the establishment of protective measures has led countries to produce better quality products and therefore more accepted internationally, protecting their internal market from foreign products, which were not yet prepared for the competition. In 1985, The United Nations positivated the principle of the consumer vulnerability, influencing the consumer law of many countries. The concern about the fundamental rights and the consumer protection consolidates human rights and promotes economic and social development. As a fundamental right, the consumer protection entails the rest of the Brazilian legislation. Therefore, the rules originated from commercial agreements that are not in accordance with our Constitution must be disregarded, while those that expand the level of the protection of the human being must be applied immediately (CF/1988). However, there is still a long way to run as far as harmonisation is concerned in order to guarantee full consumer protection inside and outside regional economic blocks. It is very important that the enacted rights are expanded and not restricted by new international rules.
\end{abstract}

Keywords: economic integration, liberalization, consumer protection. 


\section{Introdução}

Os processos de integração econômica consistem, normalmente, em acordos regionais de comércio, incrementando-se ao longo do tempo, com o objetivo de liberalização crescente de barreiras e aumento do comércio entre os países signatários. Globalização, no entanto, é um processo mais abrangente. Embora a questão econômica seja predominante, a existência de aspectos políticos e sociais é inegável. Este fenômeno acarreta sentimentos contraditórios ao redor do globo, mas, independentemente do que as pessoas pensam e sentem a este respeito, a realidade demonstra que a sociedade atual tem-se estruturado sem os limites de fronteiras. As empresas multinacionais expandem seu âmbito de atuação pressionando governos a formar acordos que possibilitem a ampliação de mercados consumidores.

Nesta esteira, vários países positivaram, em seus ordenamentos internos, o princípio da proteção do consumidor, considerado a parte mais frágil da relação de consumo ${ }^{1}$, até como forma de proteger a subsistência da economia de mercado ${ }^{2}$. Por este motivo, foi também necessário que o tema ultrapassasse fronteiras e fosse considerado nos tratados de integração, já que a desconsideração do consumidor seria um retrocesso histórico grave ${ }^{3}$.

A integração econômica e a globalização são, atualmente, meios viáveis para a realização de objetivos da humanidade, como a redução da pobreza, o avanço das relações humanas, o desenvolvimento do direito como instrumento de proteção da dignidade da pessoa humana e a igualdade das nações e dos povos. No entanto, as forças motrizes e os interesses vinculados a estes processos não têm, sempre, os mesmos objetivos. O propósito deste trabalho é analisar o contraste entre estes dois caminhos, onde se convergem, na proteção dos direitos humanos, e onde se distanciam, quando os direitos são violados pelas tendências neoliberais de livre concorrência e livre comércio.

\footnotetext{
${ }^{1}$ Para mais detalhes sobre a vulnerabilidade do consumidor, confira: SANTANA, Héctor Valverde. Prescrição e decadência nas relações de consumo. São Paulo: Revista dos Tribunais, 2002, p. 46-47.

${ }^{2}$ Cf. comentário interessante sobre a expressão "economia de mercado" em substituição à palavra "capitalismo" em: GALBRAITH, John Kenneth. A economia das fraudes inocentes. Tradução: Paulo Anthero Soares Barbosa. São Paulo: Companhia das Letras, 2004, p.18-25.

${ }^{3}$ ARRIGHI, p.126.
} 


\section{A evolução histórica da tutela do consumidor no mundo}

Um dos primeiros instrumentos de que se tem conhecimento em relação à tutela do consumidor foi o Código de Hamurabi, que, por meio das Leis 233 e 234, protegia o consumidor nos casos de serviços deficientes ${ }^{4}$. Também o Código de Massú, vigente na Mesopotâmia, no Egito Antigo e na Índia do século XIII a.C., protegia os consumidores indiretamente ao tentar regular as trocas comerciais ${ }^{5}$.

No direito romano clássico, o vendedor era responsável pelos vícios da mercadoria a menos que os ignorasse. No Período Justiniano, a responsabilidade passou a ser atribuída ao vendedor independente de seu conhecimento do vício. Se a venda tivesse sido feita de má-fé, cabia ao vendedor ressarcir o consumidor devolvendo a quantia recebida em dobro.

Nas últimas décadas, os países viram a necessidade de unir-se em blocos, a fim de reduzir barreiras tarifárias e incrementar o comércio internacional para competir no mundo globalizado. Os consumidores passaram a contar com a facilidade de poder adquirir os mais variados produtos e serviços originários de qualquer parte do mundo. Entretanto, esta facilidade também veio acompanhada de uma série de dificuldades que demonstram a fragilidade do consumidor nas relações de consumo ${ }^{6}$. Este último, atraído por ofertas e métodos agressivos de marketing, por impulso ou senso de aventura, por jogos e prêmios e por acreditar em mitos, como qualidade superior de produtos importados, novidades e dificuldades com o idioma da oferta, assume riscos pela falta de proteção legal que o ampare.

Com efeito, somente após o crescimento dos grupos de defesa do consumidor e um longo período de mobilização da opinião pública no sentido de chamar a atenção dos legisladores para adoção de medidas protetivas é que o papel do consumidor, o "protagonista esquecido” nos tratados de integração, segundo Arrighi (p.126), foi levado em consideração. O Sherman Antitrust Act de 1890 foi a primeira manifestação moderna da necessidade de proteção do consumidor. Mas, apenas em 1962, com a mensagem do Presidente Kennedy ao

\footnotetext{
${ }^{4}$ FILOMENO: 2001, p. 22.

${ }^{5}$ PERIN JUNIOR: 2003, p.6.

${ }^{6}$ Sobre a especificidade do consumo internacional e o desequilíbrio entre os fornecedores e consumidores nestas relações de consumo, cf.: MARQUES, Cláudia Lima. A proteção do consumidor de produtos e serviços estrangeiros no Brasil: primeiras observações sobre contratos à distância no comércio eletrônico. Revista de Direito do Consumidor, vol 41, p. 65.
} 
Congresso dos EUA, conhecida como “Declaração dos Direitos Essenciais do Consumidor”, pela qual se elencavam os quatro direitos básicos ${ }^{7}$, é que se consolidou a idéia de sua tutela.

Posteriormente, já na década de 70, foi a vez de a Europa manifestar-se sobre o assunto, principalmente, pelo Conselho da Europa, em 1973, e da Comunidade Econômica Européia, em 1975. Na mesma época, a Comissão de Direitos Humanos das Organizações das Nações Unidas (ONU), na 29a sessão, reconheceu como direitos fundamentais e universais do consumidor, aqueles contidos na Declaração dos Direitos Essenciais do Consumidor dos Estados Unidos.

Finalmente em 1985, a Assembléia Geral da ONU editou a resolução n. 39/248 de 10/04/1985 sobre a proteção ao consumidor, positivando o princípio da vulnerabilidade no plano internacional. As diretrizes constituíam um modelo abrangente, descrevendo oito áreas de atuação para os Estados, a fim de prover proteção ao consumidor. Entre elas: a) proteção dos consumidores diante dos riscos para sua saúde e segurança, b) promoção e proteção dos interesses econômicos dos consumidores, c) acesso dos consumidores à informação adequada, d) educação do consumidor, e) possibilidade de compensação em caso de danos, f) liberdade de formar grupos e outras organizações de consumidores e a oportunidade de apresentar suas visões nos processos decisórios que as afetem. Estas diretrizes forneceram importante conjunto de objetivos internacionalmente reconhecidos, destinados aos países em desenvolvimento, a fim de ajudá-los a estruturar e fortalecer suas políticas de proteção ao consumidor ${ }^{8}$.

Em seguida, foram aprovadas as resoluções do Conselho Econômico e Social (julho/88 e julho/90). Em nível regional, a International Organization of Consumers Unions (IOCU), uma organização não governamental mundial em defesa do consumidor, celebrou, em Montevidéu, em outubro de 1986, a primeira conferência regional para a América Latina e o Caribe. Pouco depois, em março de 1987, a ONU, também em Montevidéu, impulsionou a realização de um encontro com pouco mais de 20 países e algumas organizações de consumidores para discutir a aplicação das diretrizes no continente.

\footnotetext{
${ }^{7}$ Os quatro direitos básicos são: direito à segurança, informação, escolha e direito de ser ouvido.

${ }^{8}$ Disponível em: http://www.un.org/documents/ecosoc/cn17/1998/background/ecn171998-consumer.htm. Acesso em 10/10/2004.
} 
A partir daí, vários países passaram a abordar a questão da proteção do consumidor na jurisdição interna, adaptando ou elaborando a legislação. Brasil, Argentina, Peru, Honduras, Equador, Chile, Costa Rica, México, Paraguai e Uruguai promulgaram leis específicas sobre o tema, sendo que os três primeiros, além de El Salvador, incluíram a tutela do consumidor em suas constituições. Outros países, como Bolívia, Guatemala, Trinidad e Tobago, Nicarágua e Colômbia, estavam em processo de elaboração de suas legislações. O sucesso desta investida ocorreu graças à monitoração e à assistência da ONU aos países das Américas e da Ásia9 . Finalmente, em dezembro de 2002, a proteção do consumidor foi declarada direito fundamental pelos presidentes dos quatro Estados-membros do Mercosul ${ }^{10}$.

No entanto, é preciso notar o forte componente político-econômico nas regras de proteção (nacional) e internacional dos consumidores. Ao estabelecer normas mais protetivas, os países começam a produzir produtos de maior qualidade e, conseqüentemente, de maior aceitação internacional, além de proteger seu mercado interno de fornecedores estrangeiros não preparados para esta competição. Desta forma, o direito do consumidor regula o mercado em relação à concorrência e às políticas governamentais ${ }^{11}$.

\section{A tutela do consumidor como direito fundamental}

Para Cançado Trindade (1997, p.17), a idéia dos direitos humanos é tão antiga quanto a história das civilizações e tem como objetivo “afirmar a dignidade da pessoa humana, lutar contra todas as formas de dominação, exclusão e opressão, em prol da salvaguarda contra o despotismo e a arbitrariedade, e na asserção da participação na vida comunitária e do princípio da legitimidade”. Segundo o autor, o reconhecimento dos direitos básicos forma padrões mínimos universais de comportamento e respeito ao próximo, observando as necessidades e as responsabilidades dos seres humanos. Os direitos humanos são vinculados ao bem comum, tendo em vista a emancipação do ser humano de todo o tipo de servidão, inclusive a de ordem material.

Os direitos do homem foram conformados no século XVII, expandindo-se no século seguinte, ao tornar-se elemento básico da reformulação das instituições políticas. Atualmente,

\footnotetext{
${ }^{9}$ MARQUES: 2004, p.323.

${ }^{10}$ Ver declaração presidencial dos direitos fundamentais dos consumidores do Mercosul na íntegra em: http://www.mre.gov.br/portugues/politica_externa/mercosul/mercosul/declaracao.asp. Acesso em 10/11/04.

${ }^{11}$ MARQUES, Revista de Direito do Consumidor, vol 41, p. 66.
} 
não se denominam mais direitos do homem, mas, sim, direitos humanos, terminologia politicamente correta ${ }^{12}$. Portanto, direitos humanos fundamentais ou direitos fundamentais têm o mesmo significado ${ }^{13}$.

Bonavides (2000, p. 514-518) acredita que os direitos fundamentais são os do homem que as Constituições positivaram, recebendo nível mais elevado de garantias ou segurança. Cada Estado, pois, tem seus direitos fundamentais específicos. Entretanto, o autor acrescenta que os direitos fundamentais estão vinculados aos valores de liberdade e dignidade humana, levando-nos, assim, ao "significado de universalidade inerente a esses direitos como ideal da pessoa humana”.

Nesta mesma esteira, Canotilho (1998, p. 353-356) ensina que a positivação dos direitos fundamentais, considerados “naturais e inalienáveis” do indivíduo pela Constituição como normas fundamentais constitucionais, é que vincula o direito. Sem o reconhecimento constitucional, estes direitos seriam meramente aspirações ou ideais, seriam apenas "direitos do homem na qualidade de normas de ação moralmente justificadas”.

A doutrina, atualmente, classifica-os em direitos humanos fundamentais de primeira, segunda, terceira e quarta dimensões ${ }^{14}$ cujos conteúdos ensejariam os princípios: liberdade, igualdade e fraternidade ${ }^{15}$. Direitos de primeira dimensão ou de liberdade seriam os direitos e as garantias individuais e políticos clássicos, as chamadas liberdades públicas. Visam inibir a interferência indevida do Estado na vida do cidadão. Os direitos de segunda dimensão ou de igualdade referem-se aos direitos sociais, econômicos e culturais, surgidos no início do século XX. Eram os direitos de caráter social. Neste caso, a interferência do Estado era desejada para garantir a igualdade material dos indivíduos. Direitos de terceira dimensão ou de solidariedade ou fraternidade são os da coletividade, de titularidade coletiva ou difusa. Entre eles, encontram-se o direito à paz, ao meio ambiente equilibrado, à comunicação, à proteção do consumidor ${ }^{16}$. Bonavides (2000, p.524-526) cita a quarta dimensão de direitos originários

\footnotetext{
${ }^{12}$ FERREIRA FILHO: 1996, p. 14.

${ }^{13}$ CANOTILHO (1998, p.369) distingue os direitos do homem dos direitos fundamentais, sendo os primeiros, “direitos válidos para todos os povos e em todos os tempos”, e os segundos são os direitos do homem jurídicoinstitucionalmente garantidos e limitados no tempo e espaço.

${ }^{14}$ Note que a terminologia "direitos de primeira, segunda e terceira gerações” é duramente criticada por diversos autores já que estes direitos se completam, expandem-se, acumulam -se não se substituem ou se sucedem.

${ }^{15}$ Segundo BONAVIDES (2000, p.514 -518), a Declaração francesa de direitos do homem de 1789 procurava generalizar e universalizar estes direitos "inserindo na ordem jurídica positiva de cada ordenamento político os direitos e conteúdos materiais referentes àqueles postulados” - liberdade, igualdade e fraternidade.

${ }^{16}$ DE LUCCA: 2003, p.426.
} 
do mundo globalizado: os direitos à democracia, à informação, ao pluralismo. Seriam estes direitos que possibilitariam a legítima globalização política.

Para Cançado Trindade (1997, p.23-24), não há como dividir os direitos humanos invocando certas categorias de direitos em razão de "pretensa natureza jurídica”. Separar o econômico do social e do político a fim de negar-lhes os meios eficazes de implementação não deveria resistir aos imperativos de proteção dos direitos humanos. Assim, há a necessidade da consolidação de obrigações erga-omnes de proteção diante da concepção integral e abrangente dos direitos humanos que envolvam todos os seus direitos: civis, políticos, econômicos e culturais.

No entanto, a expansão e a generalização da proteção internacional dos direitos humanos enfrentam tentativas de categorizações de direitos, inclusive em relação às pessoas protegidas, ou pela relação com o Estado (se é um direito que proteja o homem do Estado ou pelo Estado). A I Conferência Mundial dos Direitos Humanos, realizada em Teerã, em 1968, pôs termo a esta discussão, afirmando que a realização plena dos direitos civis e políticos seria impossível sem o gozo dos direitos econômicos, sociais e culturais ${ }^{17}$.

Como visto, a partir da resolução n. 39/248 de 10/04/1985 da Organização das Nações Unidas (ONU), diversos países passaram a enfrentar a questão da proteção do consumidor incluindo o Brasil, que, juntamente com a Argentina, apresentam as melhores e as mais avançadas legislações nesta matéria no Mercosul. A Constituição da República de 1988 consagra a defesa do consumidor no artigo $5^{\circ}$, XXXII, que versa sobre os direitos e as garantias fundamentais ${ }^{18}$. Desta forma, o legislador obrigou o Estado a promover a proteção do consumidor, elevado a direito fundamental do cidadão.

A defesa do Consumidor também está prevista no artigo 170, V, da Constituição Federal brasileira, que a considerou como um dos princípios gerais da atividade e da ordem econômica. Por meio do artigo, deve-se garantir a melhoria da qualidade de vida dos cidadãos pela implementação de uma política de nacional de consumo ${ }^{19}$.

\footnotetext{
${ }^{17}$ CANÇADO TRINDADE, 1997, p. 360.

18 Artigo 5 ${ }^{\circ}$, XXXII da CF in verbis: "O Estado promoverá, na forma da lei, a defesa do consumidor".

${ }^{19}$ Artigo 170, V da CF, in verbis: "A ordem econômica, fundada na valorização do trabalho humano e na livre iniciativa, tem por fim assegurar a todos existência digna, conforme os ditames da justiça social, observados os seguintes princípios: (...) V - defesa do consumidor.”
} 
Finalmente, o Congresso Nacional conforme orientação de nossa Carta Magna, elaborou a Lei 8.078 de 11/09/1990 de proteção ao consumidor, criando o Código de Defesa do Consumidor (CDC). Por tratar-se de verdadeiro “microssistema jurídico”, já que, nele, encontram-se normas de direito penal, civil, constitucional, processuais penais, civis e administrativas, com caráter de ordem pública ${ }^{20}$, e por constituir legislação extremamente avançada, o Código Brasileiro de Defesa do Consumidor influenciou as legislações dos outros países do Mercosul. A proteção do consumidor, então, é um direito fundamental já declarado pela ONU, positivado em nossa Constituição e reconhecido pelos países-membros do Mercosul.

Há certa discussão sobre o motivo da positivação da proteção do consumidor como direito fundamental. Muitos acreditam que os argumentos que levaram à elevação deste princípio a direito fundamental são de política. Segundo Dworking ${ }^{21}$, um argumento de política justifica uma decisão política que fomente ou proteja algum objetivo coletivo da comunidade como um todo. Nesta linha, seria certo afirmar que este princípio não seria legitimamente um norte para a tomada de decisões em favor da parte mais fraca em uma relação de consumo. Também poderia pensar-se que a preocupação tão somente seria a de “defender os interesses exclusivamente econômicos do consumidor, isto é, custo-benefício economicamente mensuráveis”22.

Ora, o processo de industrialização, que teve início no final do século XIX e que se intensificou após a Segunda Guerra Mundial, culminando na década de 70, intensificou o consumo de bens e serviços em vários setores da economia mundial. Surgiram, então, os movimentos consumeristas, a fim de oferecer o contraponto para que obtivéssemos um mercado político estável e equilibrado, já que exigiriam mudanças, investimentos e políticas que abrandassem a fragilidade do consumidor nas relações de consumo. No entanto, para Macedo Jr (1998, p. 272), esta idéia é utópica, uma vez que os interesses dos consumidores são esparsos e difusos. A saúde, a proteção do meio ambiente, a proteção de informações sobre o consumidor são alguns importantes interesses que também estão em jogo. Desta forma, ampliam-se os motivos para a proteção do consumidor, ligados por princípios também já positivados no mundo todo. Surge, assim, a necessidade de tutela eficaz e abrangente,

\footnotetext{
${ }^{20}$ DORNELES: 2003, p. 46.

${ }^{21}$ Para DWORKING (2002, p.36), política é uma espécie de padrão que estabelece um objetivo a ser alcançado, em geral, uma melhoria em algum aspecto econômico, político ou social da comunidade.

22 PERIN JR: 2003, p.2.
} 
oferecida pelo Estado. A legislação consumerista é, portanto, uma conquista, é o reconhecimento de novos valores, "fundados na personalidade humana, abandonando o nítido caráter individual e patrimonialista... O homem deixa de ser objeto e passa a ser, de uma vez por todas, sujeito de direito" 23 .

\section{O impacto da liberalização do comércio sobre os direitos do consumidor}

A evolução tecnológica e a globalização dos mercados acarretaram mudanças profundas nos padrões de produção, provocando a intensificação da formação de blocos de integração e o aumento do comércio internacional, já que consumir bens e serviços se tornou extremamente fácil em face da grande oferta de variedade de produtos, marketing agressivo e preços reduzidos pela competição.

Acreditava-se na soberania do consumidor que possuía o poder de escolha entre comprar ou não comprar determinado produto. No entanto, essa idéia é considerada uma “fraude” para Galbraith (2004, p. 28-29), que acredita, em decorrência de propaganda e promoções, poderem as empresas controlar a resposta do público e, conseqüentemente, o consumo. Deste contexto, surgiu a necessidade de ampliação e aprofundamento dos mecanismos de proteção dos direitos do consumidor. A desigualdade entre o consumidor e o fornecedor nas relações de consumo, principalmente internacionais, é agravada pela diferença da língua, das normas e dos costumes, pela insegurança na entrega, pelas dificuldades na garantia, entre outros aspectos ${ }^{24}$.

No entanto, havia preocupação de que a proteção do consumidor poderia, também, tornar-se barreira ao comércio tanto de bens como serviços nos blocos de integração. Ora, se o objetivo principal dos processos de integração é sancionar uma realidade existente, a do intercâmbio comercial intenso entre os parceiros dos blocos, a fim de aumentar o volume comercial entre eles, a questão social ficou relegada ao segundo plano, aparecendo apenas a partir de determinada etapa histórica no desenvolvimento do processo de integração ${ }^{25}$.

É certo que os acordos de liberação do comércio internacional ativeram-se principal e inicialmente apenas à fixação de tarifas e à ampliação de mercados. No entanto, tem havido

\footnotetext{
${ }^{23}$ FARIAS: 2002, p. 29.

${ }^{24}$ MARQUES: 2002, p.150 e ss.

${ }^{25}$ CHALOULT \& ALMEIDA: 1999, p. 20-21.
} 
crescente preocupação das relações entre o comércio e os direitos humanos, o que inclui a tutela do consumidor. As organizações de proteção dos direitos humanos e de proteção do consumidor têm pressionado para que os acordos enfoquem outros aspectos relativos aos direitos fundamentais.

As políticas econômicas e comerciais impostas aos Estados imprimem redefinições do papel do Estado, acarretando conseqüências importantes para os consumidores. Em alguns casos, facilitando o funcionamento dos sistemas econômicos, marginalizando as empresas inidôneas e prestadoras de serviços incompetentes, consolidam-se os direitos do cidadão, promovendo o desenvolvimento econômico e social. Por outro lado, algumas políticas da OMC, por exemplo, tiveram impacto negativo nos países em via de desenvolvimento, no que tange a assuntos relativos à saúde e à biodiversidade ${ }^{26}$. Se os impactos da liberalização do comércio são positivos ou negativos, é discutível. O fato, entretanto, é que não há caminho de volta.

Se considerarmos que os princípios enunciados na Carta das Nações Unidas na Declaração Universal dos Direitos Humanos e nas resoluções da ONU constituem fonte de direito internacional e, portanto, influenciam o direito interno, então a aplicação das normas de direito internacional, decorrentes dos acordos de comércio, em conexão com interesses privados, deve estar em sintonia com o Direito Constitucional de cada Estado. Se as normas internacionais forem de encontro aos direitos fundamentais tutelados internacionalmente, devem ser desprezadas e, no caso do Brasil, se ampliarem o grau de proteção ao homem, devem ser aplicadas imediatamente, segundo o artigo 5º, parágrafos 1 e 2 da CF/ 1988. Os países mais pobres, cujos recursos são destinados ao cumprimento dos acordos comerciais, desprezam as questões sociais. Para eles, responder positivamente ao processo de globalização será muito mais árduo e demorado.

\section{O desafio da proteção do consumidor na era da globalização}

Miriam de Almeida Souza ${ }^{27}$ tem a seguinte visão sobre a era da globalização:

“...os países do Terceiro Mundo dificilmente terão condições de concorrer livremente no mercado internacional, ainda mais por esta barreira alfandegária representada pelos novos, e cada vez mais complexos, conceitos de competitividade e qualidade exigidos pelo consumidor nos países

\footnotetext{
${ }^{26}$ REIS: 2005, p. 167.

${ }^{27}$ In: DE LUCCA, Newton. Direito do Consumidor. São Paulo. Quartier Latin, 2003, p. 437. 
avançados, já em muitos produtos, em face de uma crescente conscientização dos interesses difusos. Tampouco tem o Terceiro Mundo condição de resistir a uma torrente de produtos perigosos e resíduos tóxicos oriundos dos países desenvolvidos, faltando-lhe a informação, a capacidade técnica de verificação, a capacidade administrativa para a fiscalização, e, muitas vezes, a vontade política necessária das elites locais. Perante tais desvantagens esmagadoras, essa atitude conivente dos governos dos países desenvolvidos deve ser considerada cúmplice de um crime de lesahumanidade, em vista dos males causados às populações e ao meioambiente, tornando-os assim, ainda mais debilitados.”

É certo que, neste contexto, a tutela dos consumidores faz-se mister, e a globalização cria a necessidade da atuação Estatal para a proteção do indivíduo e, conseqüentemente, da sociedade nas relações de consumo, já que a produção e a comercialização global de bens e serviços acarretam demanda de proteção também global. A fim de reverter a previsão de Miriam de Almeida Souza, por muitos aclamada, é preciso que o direito do consumidor se desenvolva de acordo com princípios de garantias básicas e fundamentais já positivados internacionalmente e internamente.

Ora, uma sólida política de proteção dos consumidores colabora para a regulamentação e o equilíbrio do mercado, contribuindo para a garantia de economia mais eficiente. No entanto, é preciso lembrar que o desenvolvimento da internet e a velocidade cada vez maior das informações podem atropelar os mecanismos de proteção dos consumidores. A União Européia tem sido capaz de responder rapidamente à demanda, uma vez que os países-membros têm de adaptar suas legislações para atender a norma supraconstitucional acordada.

No caso do Brasil, especificamente em relação ao Mercosul, há receio de que, em decorrência de serem mais refinadas, nossas regras venham impor barreiras desnecessárias ao comércio intrabloco. No entanto, o que se vê, é que elas foram referência para as legislações dos outros países, uma vez que há a consciência de que os diferentes níveis de proteção do consumidor possam representar aspecto negativo para o comércio. É também reconhecido que o nível de proteção não deve ser reduzido, apesar da falta de um tribunal supraconstitucional para assegurar a tutela a todos os consumidores do bloco que passariam a ter "direitos iguais nas relações de consumo estabelecidas em tal âmbito” e deixariam de ser apenas mais um 
consumidor nacional de cada país, com atribuição de direitos distintos, para serem um consumidor latino-americano ${ }^{28}$.

\section{Conclusão}

A formação dos blocos econômicos e o processo da globalização acarretam interdependência entre os países cada vez maior na economia mundial. Neste contexto, surge o movimento consumerista para forçar a ampliação e a aplicação de políticas legislativas e de proteção ao consumidor tanto no âmbito interno quanto internacional.

Apesar de muitos considerarem que esta tutela pode constituir barreira ao comércio e limitações para o produtor de países menos desenvolvidos, a verdade é que a maior concorrência fez com que os consumidores do mundo tivessem maior acesso a produtos mais baratos e de maior qualidade. Por outro lado, a hipossuficiência do consumidor nas relações de consumo, principalmente nas internacionais, mostrou-se gritante.

A fim de minimizar esta diferença entre as partes produtoras e fornecedoras de bens e serviços e consumidores, cujos interesses são individuais e difusos, tem havido a tendência à adoção de padrões internacionais para regulamentação de produtos. Historicamente, isso pode ser comprovado pelas diretrizes legais da União Européia ${ }^{29}$, da Organização para a Cooperação Econômica e Desenvolvimento (OECD) ${ }^{30}$ e das Nações Unidas.

Estas medidas influenciam o cenário econômico-político global. Os países em desenvolvimento, como o Brasil, que lutam para atingir maior equilíbrio de suas balanças comerciais sofrerão impacto com o que as legislações de proteção ao consumidor de países mais desenvolvidos irão exigir. Em contrapartida, as medidas forçam os países a modernizarse para competir no mundo globalizado e oferecer a sua sociedade produtos de alta qualidade e preços mais baixos.

\footnotetext{
${ }^{28}$ DE LUCCA: 2000, p. 110.

${ }^{29}$ Segundo as diretrizes da UE, qualquer país que, com ela, quiser manter relações comerciais deverá aceitar os padrões de qualidade estipulados, o que determina um padrão de qualidade mundial, haja vista o peso comercial que a UE possui no cenário internacional.

${ }^{30}$ Para a OECD, as práticas comerciais e a concorrência restritiva são lesivas aos interesses dos consumidores. Esta mentalidade representa um avanço no direito do consumidor internacional.
} 
Para garantir este avanço, é necessário promover harmonização ${ }^{31}$ ou convergência de legislações. Isto já acontece nos países da União Européia e, em menor escala, entre os países do NAFTA. Provavelmente, irá acontecer entre os países do Mercosul. É mister que isso seja feito de forma ágil, uma vez que o desenvolvimento da tecnologia e a velocidade nas mudanças levam à facilidade em consumir. Também será imprescindível a observação das garantias já positivadas em nível nacional a fim de que o direito do consumidor seja ampliado e não restringido pelas novas normas internacionais.

\section{Referências}

ARRIGHI, Jean Michel. La protección de los consumidores y el Mercosur. Revista de Direito do Consumidor, São Paulo, n. 2, p. 124-136, jun. 1992.

BONAVIDES, Paulo. Curso de direito constitucional. São Paulo: Malheiros, 2000.

BRASIL. Ministério das Relações Exteriores. Declaração presidencial dos direitos fundamentais dos consumidores do mercosul. Brasília, 2000. Disponível em: <http://www.mre.gov.br/portugues/politica_externa/mercosul/mercosul/declaracao.asp>. Acesso em: 10 nov. 2004

CANOTILHO, J. J. Gomes. Direito constitucional e teoria da constituição. Coimbra: Almedina, 1998.

CHALOULT, Yves; ALMEIDA, Paulo Roberto de. (Org.). Mercosul, NAFTA e ALCA: a imensão social. São Paulo: LTr, 1999.

DE LUCCA, Newton. Direito do consumidor: aspectos práticos. Bauru: Edipro, 2000.

Direito do consumidor. São Paulo: Quartier Latin, 2003.

DORNELES, Renato Moreira. Tutela administrativa dos consumidores no Brasil como paradigma aos países do mercosul. Curitiba: Juruá, 2003.

DWORKING, Ronald. Levando os direitos a sério. São Paulo: M. Fontes, 2002.

\footnotetext{
${ }^{31}$ MARQUES (1999, p. 21) propõe a adoção de harmonização fragmentada como a solução apresentada pela Comunidade Européia.
} 
FERREIRA FILHO, Manoel Gonçalves. Direitos humanos fundamentais. São Paulo: Saraiva, 1996.

FILOMENO, José Geraldo Brito. Manual de direitos do consumidor. São Paulo: Atlas, 2001.

GALBRAITH, John Kenneth. A economia das fraudes inocentes. Tradução Paulo Anthero Soares Barbosa. São Paulo: Companhia das Letras, 2004.

MACEDO JR, Ronaldo Porto. Contratos relacionais e defesa do consumidor. São Paulo: Max Limonad, 1998.

MARQUES, Cláudia Lima. Direitos do consumidor no mercosul. Revista de Direito do Consumidor, São Paulo, v. 32,1999.

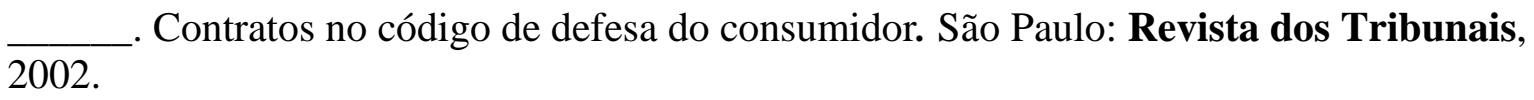

. A proteção do consumidor de produtos e serviços estrangeiros no Brasil: primeiras observações sobre contratos à distância no comércio eletrônico. Revista de Direito do Consumidor, n. 41, p.39-80, jan./mar. 2002.

Confiança no comércio eletrônico e a proteção do consumidor - um estudo dos negócios jurídicos de consumo no comércio eletrônico. São Paulo: Revista dos Tribunais, 2004.

PERIN JUNIOR, Ecio. A globalização e o direito do consumidor: aspectos relevantes sobre a harmonização legislativa dentro dos mercados regionais. Barueri: Manole, 2003.

REIS, Henrique Marcello dos. Relações econômicas internacionais e direitos humanos. São Paulo: Quartier Latin, 2005.

SANTANA, Héctor Valverde. Prescrição e decadência nas relações de consumo. São Paulo: Revista dos Tribunais, 2002.

TRINDADE, Antônio Augusto Cançado. Tratado de direito internacional dos direitos humanos. Porto Alegre: S. A. Fabris, 1997. v. 1. 
UNITED NATIONS. Commission on Sustainable Development. Consumer protection and sustainable consumption: new guidelines for the global consumer. São Paulo, 1998.

Disponível em: <http://www.un.org/documents/ecosoc/cn17/1998/background/ecn171998consumer.htm>. 